Article

\title{
Population Dynamics of Hyalomma dromedarii on Camels in the United Arab Emirates
}

\author{
Nighat Perveen, Sabir Bin Muzaffar ${ }^{\mathbb{D}}$ and Mohammad Ali Al-Deeb* \\ Department of Biology, United Arab Emirates University, Al Ain 15551, UAE; 201790740@uaeu.ac.ae (N.P.); \\ s_muzaffar@uaeu.ac.ae (S.B.M.) \\ * Correspondence: m_aldeeb@uaeu.ac.ae; Tel.: +971-3-713 6527
}

Received: 28 March 2020; Accepted: 21 May 2020; Published: 23 May 2020

\begin{abstract}
Hyalomma dromedarii is the most important tick species infesting camels in the Middle East. So far, there are no studies on the population dynamics of $H$. dromedarii ticks on camels in the United Arab Emirates (UAE). Thus, the current study was performed: (1) to assess H. dromedarii population dynamics under common camel breeding and management practices in the study area, (2) to evaluate H. dromedarii life stage changes and sex ratio over time, and (3) to measure parasitological indicators of H. dromedarii infestation. We conducted monthly on-site tick visual counts and collection from camels in $\mathrm{Al}$ Ain, $\mathrm{UAE}$, over 12 months. Our results show that the infestation prevalence was very high during the whole study period, with a mean of $94.33 \%$. The maximum infestation intensity occurred in June, while the minimum occurred in January. Overall, $H$. dromedarii ticks were found on camels during the entire year in spite of monthly applications of an acaricide. This study reveals that $H$. dromedarii has a very high prevalence and continuous presence on camels in the UAE regardless of the weather fluctuations and acaricide applications and showed the need for an effective control strategy.
\end{abstract}

Keywords: camel; ticks; Hyalomma dromedarii; population dynamics; United Arab Emirates

\section{Introduction}

Ticks are globally considered important arthropod vectors due to the wide variety of human and animal pathogens they can transmit [1]. Since many pathogens exhibit a certain degree of vector specificity, the information on the distribution patterns and phenology of ticks is key in identifying disease foci and seasonality. This information could then be used to formulate control measures [2]. Microclimate features and the relative abundance of some key hosts impact the seasonal patterns of tick activity, their distribution, and the persistence of foci of pathogens [3]. Temperature and relative humidity affect tick host-seeking behavior and survival rates [2,4] and regulate the duration of questing periods as well as the territory with suitable environmental conditions.

The Middle East and North Africa is a hyperarid region connecting Africa to Eurasia [5,6]. Camel farming in these regions, particularly in the Middle East, has become enhanced in recent years with increasing levels of economic development. The United Arab Emirates, in particular, vastly improved development on account of its situation as a trade hub [7]. However, almost $98 \%$ of the UAE, a region extending from the Sultan of Oman to the Kingdom of Saudi Arabia, is covered by deserts and is home to a large camel population of approximately 459,000 camel heads [8]. Camels have unique browsing behavior, which makes this species superior to small ruminants in conserving vegetation cover [9]. The camel tick Hyalomma dromedarii feeds primarily on camels. However, in Mauritania, it appears to be the main vector of Theileria annulata in cattle where camels are reared alongside cattle [10]. Thus, rearing camels in mixed herds, including cattle, could contribute towards a wider exchange of pathogens [11]. 
Hyalomma dromedarii can transmit viruses such as the Crimean-Congo hemorrhagic fever virus [12,13], Dera-Ghazi-Khan virus, Dhori virus [14], and Kadam virus [15]. In addition, H. dromedarii is a vector of protozoan diseases, including theileriosis in camels (Theileria camelensis) and in cattle, (T. annulata) [14], and bacterial diseases such as $Q$ fever (Coxiella burnetii) [16] and spotted fever rickettsia [17]. The patterns of tick-host-pathogen interrelationships are changing due to shifting population densities of ticks, tick-borne infections, and the changing density of hosts [18-20]. Facts about the epidemiology of tick-borne diseases, especially on the transmission dynamics in tick vectors, is essential for the formulation of efficient control strategies [20,21].

In the UAE, the work on the ticks on camels is limited, despite the vital role that camels play in the livelihood of Emirati society and the likely impact of ticks on their productivity. Information on the tick species found on camels and their seasonal population dynamics is essential for designing and instigating effective control strategies in the country. The present work was, therefore, initiated to generate the information on these ticks and their seasonal abundance. The objectives of the study are: (1) to assess the $H$. dromedarii population fluctuation over time under common camel breeding and management practices in the study area, (2) to evaluate $H$. dromedarii's life stage changes and sex ratio over time, and (3) to measure the parasitological indicators of an $\mathrm{H}$. dromedarii infestation.

\section{Materials and Methods}

\subsection{Study Area/Site}

The study was carried out on a private farm near Umm Al Zammol Road, Al Dhaharah, Al Ain, located about $120 \mathrm{~km}$ south-southeast of Abu Dhabi (N 24 $11^{\prime}$ E $55^{\circ} 45^{\prime}$ ). Al Ain covers an area of approximately $13,100 \mathrm{~km}^{2}$. The inland location of Al Ain makes its environment warmer and drier compared to Abu Dhabi and Dubai. The vegetation cover comprises of sparse halophytes. This region is characterized by high amplitudes of seasonal temperatures, with mean monthly temperatures in the study area varying between $17.1^{\circ} \mathrm{C}$ in winter and $38.1^{\circ} \mathrm{C}$ in summer. Annual rainfall averages 91.1-201.0 $\mathrm{mm}$ [22]. The owner of the farm treated the camels with the acaricide Phoxim (Ectofox ${ }^{\circledR} 50$ EC; Dammam, Saudi Arabia; http://www.montajat.biz) monthly (during the whole year), which is a common practice among all camel breeders in Al Ain region. The acaricide was sprayed on the animals at a known concentration $(2 \mathrm{~mL} / 1 \mathrm{~L}$ of water). We recognize that this influences the actual population dynamics of the ticks. However, one of the goals of this study is to assess H. dromedarii population fluctuation over time under common camel breeding and management practices in the study area. We, therefore, monitored the population dynamics in spite of acaricide use.

\subsection{Selection of Camels for Survey}

The current study was conducted on a farm, which had 30 local breed camels ( 25 females, 1 male and 4 calves). Camels were separated from sheep and goats on the farm by a fence. A total of 25 adult camels (24 females and 1 male) aged 3-14 years were chosen and included in the survey. They were examined monthly from March 2019 to February 2020. The origin, breed, age, sex, and reproduction status of animals were recorded at the beginning of the study [23]. Most individuals were reproductively active, with the exception of four calves. Tick collection was carried out in strict accordance with the recommendations of the Animal Research Ethics Committee (A-REC) of the UAE University (ethical approval\# ERA_2019_5953). In addition, the experimental protocol was approved by the Animal Ethics Committee of UAE University.

\subsection{Tick Count and Identification}

On each monthly tick collection, all visible ticks were removed manually using forceps from the entire right side of the body of each animal. The right side was arbitrarily selected for this purpose. The number of ticks collected was doubled to determine the approximate tick load per camel [24]. Ticks were retained in $50 \mathrm{~mL}$ plastic vials. The vials containing ticks were placed on ice inside a cool 
box and were taken to the Entomology Laboratory at UAE University, where they were frozen at $-80{ }^{\circ} \mathrm{C}$ until further processing. All ticks were counted. Labeling for all specimens included location, host, and date of sampling. Ticks were morphologically identified under a stereomicroscope using available taxonomic keys $[14,25,26]$ and classified according to species, sex, and stage of engorgement.

\subsection{Parasitological Indicators}

The following parasitological indicators [9] were determined:

Infestation prevalence $(\%)=100 \times$ number of infested animals/total number of animals

Infestation intensity $=$ number of ticks/number of infested animals

Tick load $=$ number of ticks/total number of animals

\subsection{Meteorological Data Collection}

We mainly studied the effects of temperature and humidity because this study was conducted in a desert ecosystem wherein these are the major factors affecting every living thing. We used meteorological data from the nearest meteorological station. The mean monthly relative humidity $(\mathrm{RH})$ was in percent, and the mean monthly temperature was in degrees Celsius $\left({ }^{\circ} \mathrm{C}\right)$.

\subsection{Statistical Analysis}

The relationship between the monthly tick average burdens and the monthly average temperature was assessed through the Pearson correlation test using GraphPad Prism 8.3.1 for Windows (San Diego, CA, USA, www.graphpad.com). Tick loads (number of ticks per host) were compared between different months by One-way ANOVA. In addition, descriptive statistics of tick counts and percentages for male and female ticks and life stages were calculated.

\section{Results}

During the 12 visits, 2658 ticks (all $H$. dromedarii), of which 216 were nymphs, were collected from camels $(n=25)$. No larvae were detected from any of the camels. The sex ratio of the ticks (M: F) was 65.7: 34.3. Tick activity showed a peak in June (total tick burden $=479$ ) and a minimum in November (total tick burden $=120$ ) (Figure 1). The infestation prevalence was high during the whole survey, with a mean of $94.33 \%$ (Table 1). All the camels were infested with ticks throughout the year, and from March 2019 to October 2019, the infestation prevalence was 100\% (Table 1). The preference sites of ticks were the humid skin regions. Most of the collected ticks were found attached to the perianal and vulvar regions, the inner surface of thighs, udder, and inguinal region, whereas fewer ticks were collected from the pinna, and the chest region. The mean overall intensity of infestation was 18.52, whereas the relative abundance was 17.72 ticks/animal. The maximum infestation intensity was 38.32 ticks/animal in June 2019, and the minimum was 15.6 ticks/animal in January 2020 (Table 1). The correlation between the tick average burdens and the monthly average temperature was not significant $(r=0.3646, p=0.2439)$ (Figure 1$)$. In addition, the correlation between the tick average burdens and monthly average relative humidity was not significant $(\mathrm{r}=-0.54, p=0.0694)$ (Figure 1$)$. Nymphs were found in maximum percentage during March however, the numbers reached zero in June and November (Figure 2). Male ticks were present in maximum numbers throughout the entire year on camels, as compared to females (Figure 3). There was a significant difference in tick burden between the collection periods (12 months) $(\mathrm{F}=9.310, \mathrm{df}=11,288, p<0.0001)$. 


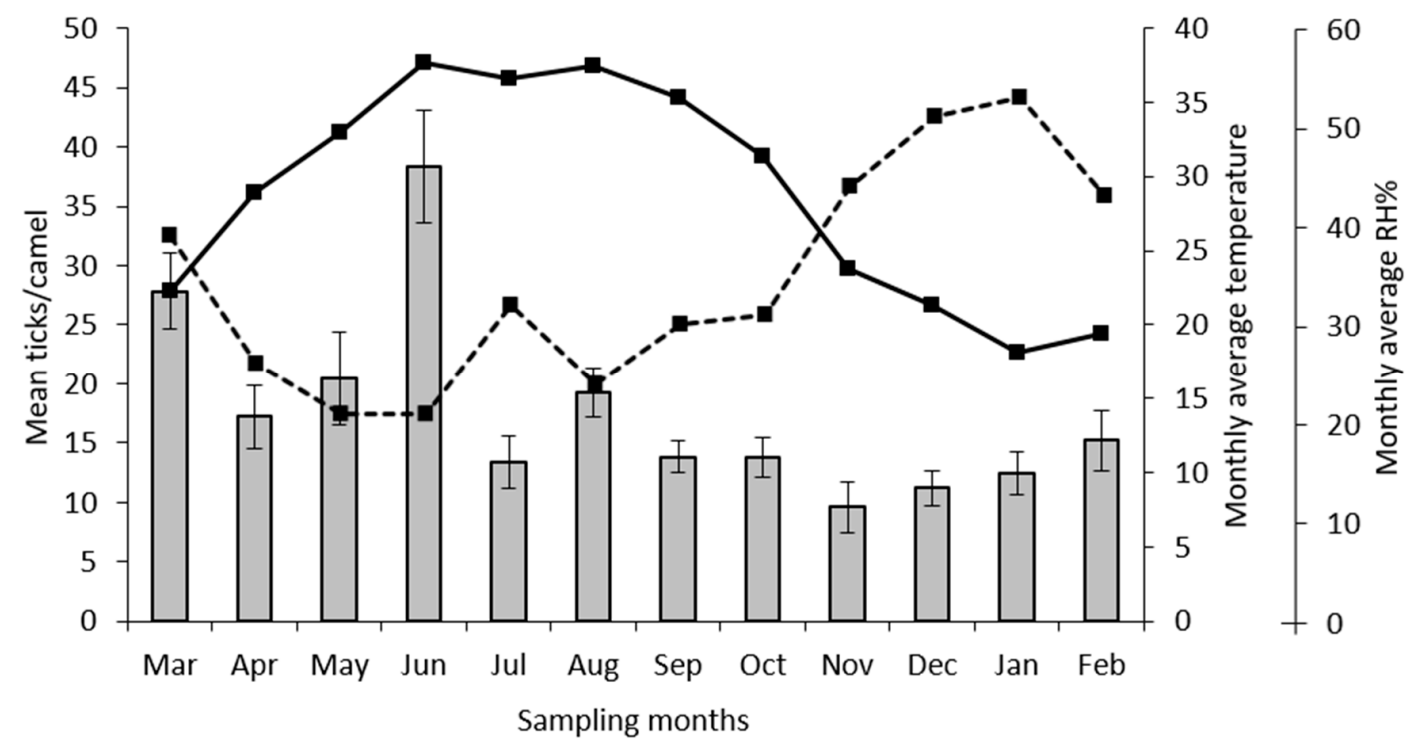

Figure 1. Fluctuation of $H$. dromedarii tick load on camels in Al Ain, UAE. Continuous line: monthly average temperature $\left({ }^{\circ} \mathrm{C}\right)$. Dotted line: monthly average relative humidity $(\%)$. Column: mean $( \pm \mathrm{SE})$ monthly ticks/camel from March 2019 to February 2020.

Table 1. Prevalence and infestation intensity of H. dromedarii tick on camels in Al Ain, UAE.

\begin{tabular}{cccccc}
\hline Year-Month & $\begin{array}{c}\text { Total Examined } \\
\text { Animals }\end{array}$ & $\begin{array}{c}\text { Total Infested } \\
\text { Animals }\end{array}$ & No. of Ticks & Prevalence \% & $\begin{array}{c}\text { Infestation } \\
\text { Intensity }\end{array}$ \\
\hline 19-March & 25 & 25 & 696 & 100 & 27.84 \\
19-April & 25 & 25 & 430 & 100 & 17.2 \\
19-May & 25 & 25 & 512 & 100 & 20.48 \\
19-June & 25 & 25 & 958 & 100 & 38.32 \\
19-July & 25 & 25 & 334 & 100 & 13.36 \\
19-August & 25 & 25 & 482 & 100 & 19.28 \\
19-September & 25 & 25 & 346 & 100 & 13.84 \\
19-October & 25 & 25 & 346 & 100 & 13.84 \\
19-November & 25 & 19 & 240 & 76 & 12.63 \\
19-December & 25 & 21 & 280 & 84 & 13.33 \\
20-Janauary & 25 & 20 & 312 & 80 & 15.6 \\
20-February & 25 & 23 & 380 & 92 & 16.52 \\
\hline
\end{tabular}

Overall prevalence: $94.33 \%$, Mean infestation intensity: 18.52 .

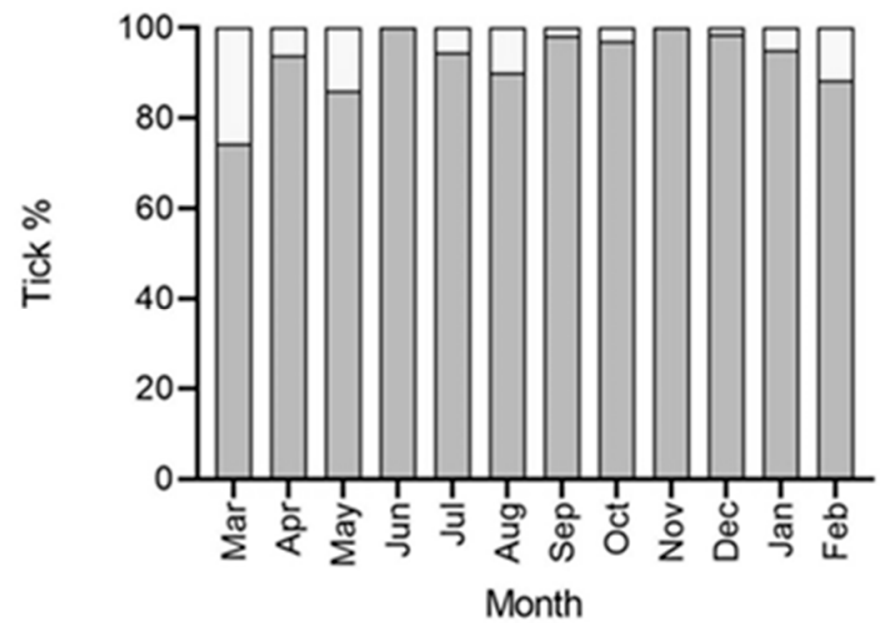

Nymphs

Adults

Figure 2. Adult and nymph H. dromedarii tick percentages on camels over twelve months (March 2019 to February 2020) in Al Ain, UAE. 


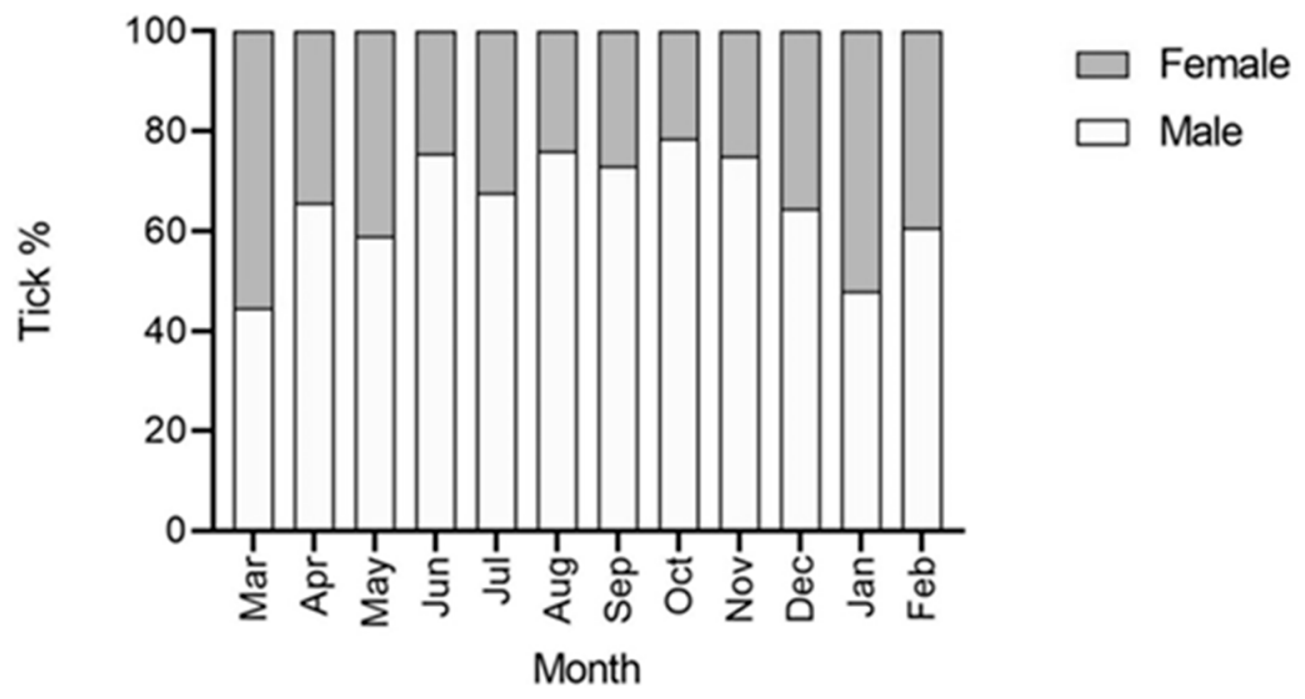

Figure 3. Adult male and female $H$. dromedarii tick percentages on camels over twelve months (March 2019 to February 2020) in Al Ain, UAE.

\section{Discussion}

Hyalomma ticks in general and H. dromedarii, in particular, have considerable economic importance, because they are major parasites of domestic animals and efficient vectors of a variety of disease-causing organisms. Hyalomma populations survive in inclement environments and are affected by extremes in temperature, humidity, and host condition [25]. Extraordinary survival factors play a large role in permitting these ticks to exist and even thrive, where few or no others live. Therefore, H. dromedarii can cause serious damage in the UAE because there are large populations of domestic camels in the country, and H. dromedarii is one of their major pests [27].

In the current study, we evaluated fluctuations in numbers of $H$. dromedarii over time under common camel breeding and management practices in the study area. Our results revealed that $H$. dromedarii ticks were on the camels throughout the entire year despite a monthly application of an acaricide by the owner of the camels. This is a very important finding because it shows that infested camels are under continuous parasitic pressure all the time, and consequently, they suffer from blood loss and possible disease infections. Furthermore, the constant presence of $H$. dromedarii ticks on camels even after application of an acaricide may indicate that either they developed acaricide resistance as a result of repeated exposure to the same chemical or there is an inadequate acaricide application. Both scenarios are valid and require investigation in future studies. In the present study, a peak in activity of adult $H$. dromedarii was observed in June 2019, which is consistent with the findings of Gharbi et al. [28] from Tunisia and Benchikh-Elfegoun et al. [29] from Algeria, where a peak activity of adult Hyalomma scupense on cattle was reported in June. In addition, $H$. dromedarii remained active throughout the year, confirming previous results in Egypt and Tunisia [9,30]. Furthermore, H. dromedarii ticks were reported with high percentages in the current study (94.33\% overall prevalence), which is similar to records from Egypt (95.6\%) [30] and the UAE (98\%) in the period 2010-2011 [27]. The life cycle of Hyalomma may be greatly lengthened in unfavorable climatic conditions, or shortened under optimum conditions [25]. Some studies indicated that total monthly tick burdens were positively correlated with several abiotic factors, for instance, monthly mean minimal temperature, monthly mean maximal temperature, and the number of sunny days, while negatively correlated with relative humidity [9]. In this study, based on the Pearson's correlation test, we can say that there is a weak positive correlation $(r=0.36)$ between tick loads and monthly average temperatures, and also there is a moderate negative correlation $(\mathrm{r}=-0.54)$ between tick loads and relative humidity. However, based on the $p$ values ( $p=0.2439, p=0.0694$; respectively) of the test, we should statistically say that the correlation is not significant $(p>0.05)$. Nonetheless, it should be mentioned here that the value 
of the Pearson's correlation coefficient is independent of sample size, whereas the $\mathrm{p}$ value is affected by sample size, which is 12 data points in this study. Therefore, future studies may have a better chance of finding that the above-mentioned two correlations are statistically significant if they use a larger sample size $(n>12)$. Our results show that there was a significant difference in tick burden between the months. The relationship between abiotic factors and tick burdens is known for different tick species, although this has not been demonstrated in arid areas where high temperatures and low relative humidity significantly influence tick dynamics. Nevertheless, because ticks were present during all months of the year, these abiotic factors may influence tick populations, but do not reduce their activity [9].

In this study, we did not find larvae on camels during the 12 months of sampling. In addition, the nymph count was very low, and thus we assume that H. dromedarii in the UAE is a tick that has a two-host lifecycle, and most likely the larval and nymphal stages feed on alternate hosts such as birds, reptiles, or small mammals. The natural life cycle of Hyalomma ticks may be altered by the host availability, host size, host density as well as microclimatic factors in the environment of the host (especially in captivity) [25]. In their immature stages, they often feed on birds, rodents, and hares that are important reservoirs of pathogens, especially viruses and rickettsiae [25]. Hyalomma dromedarii can behave as a three-, two-, or one-host species [25,26], and it is believed that the two-host life cycle is the most common for this species [14]. Hyalomma dromedarii fed on rabbits under laboratory conditions and behaved as a two-host tick [31]. However, it was found that H. dromedarii was usually a three-host tick and became a two-host tick when density on the host was high [32]. Camels are the principal hosts of the adults, which also parasitize other domestic ungulates, such as cattle, sheep, buffaloes, horses, donkeys, and goats $[14,25,33,34]$. The occasional records of adults from dogs, hyenas, ostriches, lizards, and humans were also reported [14,33]. In addition, H. dromedarii is the only species of the genus Hyalomma in which the immature stages can use both small and large mammals as hosts. Nymphs and larvae both may use the same species of large animals (especially camels) as the adults [35]. However, the immature stages can also parasitize rodents, leporids, and hedgehogs, as well as birds and reptiles $[25,33,36]$. This was confirmed in one study on ticks of wildlife from Saudi Arabia, where seventeen Hyalomma nymphs were collected from an Arabian spiny mouse (Acomys dimidiatus), and nine nymphs were collected from Sundevall's jird (Meriones crassus) which were later molted to H. dromedarii and H. impeltatum [37]. Based on the design and available resources, the focus of the current study was to collect ticks only from camels (the main host). Therefore, our results shed light on a major part of the life cycle of $H$. dromedarii, and specifically the damaging stages (adult and nymphs), which cause economic damage to the camel industry as a result of blood loss and disease transmission.

Compared to females, males were more dominant throughout the year on camels in our study. In Saudi Arabia, males were recorded in larger numbers as compared to females of $H$. dromedarii during a study of tick infestation on livestock [35]. The engorged female of $H$. dromedarii probably burrows a few centimeters below the ground surface to find favorable microhabitats for egg deposition and to protect the eggs and emerging larvae against high temperature and low humidity during the dry season [31]. This is also consistent with our assumption that larvae and nymphs feed on small mammals since these burrows are often occupied by rodents or insectivores. Future studies in the UAE need to focus on these two stages (egg and larvae) of $H$. dromedarii to understand the full life cycle and to identify secondary hosts. In addition, the seasonal production of eggs (laying locations and dates) needs to be investigated. Based on the results of this study, engorged females are encountered in almost every sampling date throughout the year. However, we did not dissect engorged females to check the presence of eggs or to quantify egg loads. Nonetheless, in December 2019, we kept some live engorged females in plastic ventilated vials in the laboratory until they laid eggs. We, therefore, suspect that eggs are laid throughout the year given the high abundance of engorged ticks year-round.

It is very common in $\mathrm{Al}$ Ain, and many places in the UAE, to find that camels are kept with sheep and goats in the same area on the farm and that they are only separated by a small net fence. This was the situation on the farm on which the current study was conducted. Periodically, 
camels were left to graze freely in the desert, for grooming and eating different desert plants. When $H$. dromedarii and $H$. impeltatum ticks are highly prevalent on camels, and they are subsequently allowed to graze together with a large number of sheep, there is a risk of ticks finding alternative hosts and becoming established [10]. In addition, it was reported that in areas where camels and cattle coexist, $H$. dromedarii might act as a vector of T. annulata [10]. In Tunisia, where camels shared common pastures with cattle [38], there was a frequent infestation of ticks originating from camels to other livestock such as cattle. This resulted in a higher tick burden and possibly an altered tick distribution on cattle. For example, H. dromedarii was the dominant tick (82.09\%) infesting cattle, followed by H. impeltatum, H. marginatum, H. scupense, and only one individual of Rhipicephalus sanguineus [38]. Hyalomma dromedarii is a vector of many viral, bacterial, and protozoan pathogens. Many genera of viruses have been isolated from $H$. dromedarii, namely Crimean-Congo hemorrhagic fever virus, Kadam virus, Dera-Ghazi-Khan Virus, and Dhori virus. In addition, the species serves as a vector for bacterial pathogen transmission such as C. burnetti, T. camelensis, and T. annulata [14,39]. Thus, it is very important to characterize the pathogenic organisms associated with ticks, given the high densities of camels and ticks in the region.

\section{Conclusions}

This is the first camel tick population dynamics study in the UAE. It shows that $H$. dromedarii ticks have a constant presence on camels without any temporal gaps, which indicates that camels are under infestation throughout the year. Furthermore, it stipulates the magnitude of the tick problem and the probable lack of success of chemical control. Further studies are needed to improve our knowledge on $H$. dromedarii life cycle, tick phenology, and their interaction with the tick fauna of other animal species. Moreover, strategic tick control may be implemented from March to June, which is the time of the tick population peak. This study advances our knowledge about $H$. dromedarii and establishes a foundation for effective and timely control.

Author Contributions: Conceptualization, M.A.A.-D. and S.B.M.; Methodology, M.A.A.-D. and S.B.M.; Formal Analysis, N.P. and M.A.A.-D.; Investigation, N.P.; Writing - Original Draft Preparation, N.P., S.B.M., and M.A.A.-D.; Writing - Review \& Editing, N.P., S.B.M., and M.A.A.-D.; Visualization, N.P. and M.A.A.-D.; Supervision, M.A.A.-D.; Project Administration, M.A.A.-D.; Funding Acquisition, M.A.A.-D. and S.B.M. All authors have read and agreed to the published version of the manuscript.

Funding: The funding of this study was provided by the UAE University through UPAR grant \# G00002604.

Acknowledgments: We thank Amjad Saeed for his help in tick collection, Ruwaya Al Kendi for her support and cooperation, and Salwa Sultan for administrative assistance. In addition, we thank UAE University Transportation Department for providing vehicles for field work.

Conflicts of Interest: The authors have no competing interests to declare.

Ethics Statement: Tick collection was carried out in strict accordance with the recommendations of the Animal Research Ethics Committee (A-REC) of the UAE University (ethical approval\# ERA_2019_5953). In addition, the experimental protocol was approved by the UAE University Research Office.

\section{References}

1. Jongejan, F.; Uilenberg, G. The global importance of ticks. Parasitology 2004, 129, S3-S14. [CrossRef] [PubMed]

2. Parola, P.; Raoult, D. Ticks and tickborne bacterial diseases in humans: An emerging infectious threat. Clin. Infect. Dis. 2001, 32, 897-928. [CrossRef] [PubMed]

3. Alonso-Carne, J.; Garcı'a-Martın, A.; Estrada-Pena, A. Assessing the statistical relationships among water-derived climate variables, rainfall, and remotely sensed features of vegetation: Implications for evaluating the habitat of ticks. Exp. Appl. Acarol. 2014, 65, 107-124. [CrossRef] [PubMed]

4. Ruiz-fons, F.; Fernández-de-mera, I.G.; Acevedo, P.; Gortázar, C.; de la Fuente, J. Factors driving the abundance of Ixodes ricinus ticks and the prevalence of zoonotic I. ricinus-borne pathogens in natural foci. Appl. Environ. Microbiol. 2012, 78, 2669-2676. [CrossRef]

5. Abahussain, A.A.; Abdu, A.S.; Al-Zubari, W.K.; El-Deen, N.A.; Abdul-Raheem, M. Desertification in the Arab region: Analysis of current status and trends. J. Arid Environ. 2002, 51, 521-545. [CrossRef] 
6. Khan, Z.I. The Arab World—An Arab Perspective; The Milli Gazette: Delhi, India, 16-31 March 2013; p. 16.

7. Gardner, A.S.; Howarth, B. Urbanisation in the United Arab Emirates: The challenges for ecological mitigation in a rapidly developing country. BioRisk 2009, 38, 27-38. [CrossRef]

8. FCSA. Livestock Statistics. Fedral Competitiveness and Statistics Authority: UAE. Available online: https://fcsa.gov.ae/en-us/Pages/Statistics/Statistics.aspx (accessed on 23 July 2019).

9. Gharbi, M.; Moussi, N.; Jedidi, M.; Mhadhbi, M.; Sassi, L. Population dynamics of ticks infesting the one-humped camel (Camelus dromedarius) in central Tunisia. Ticks Tick. Borne. Dis. 2013, 4, 488-491. [CrossRef]

10. Jacquiet, P.; Colas, F.; Cheikh, D.; Thiam, E.; Ly, B.A. Epidémiologie descriptive de la theilériose bovine à Theileria annulata en Mauritanie, Afrique de 1' Ouest sub-saharienne. Epidemiologie 1994, 47, 147-155.

11. Tomassone, L.; Grego, E.; Callà, G.; Rodighiero, P.; Pressi, G.; Gebre, S.; Zeleke, B.; De Meneghi, D. Ticks and tick-borne pathogens in livestock from nomadic herds in the Somali Region, Ethiopia. Exp. Appl. Acarol. 2012, 56, 391-401. [CrossRef]

12. Hoogstraal, H. The epidemiology of tick-borne Crimean-Congo hemorrhagic fever in Asia, Europe and Africa. J. Med. Entomol. 1979, 15, 307-417. [CrossRef]

13. Rodriguez, L.L.; Maupin, G.; Ksiazek, T.G.; Rollin, P.E.; Khan, A.L.S.; Schwarz, T.E.; Lofts, R.S.; Smith, J.F.; Noor, A.M.; Peters, C.J.; et al. Molecular investigation of a multisource outbreak of Crimean Congo hemorrhagic fever in the United Arab Emirates. Am. J. Trop. Med. Hyg. 1997, 57, 512-518. [CrossRef] [PubMed]

14. Hoogstraal, H.; Wassef, H.Y.; Buttiker, W. Ticks of Saudi Arabia fam. Argasidae, Ixodidae. Fauna Arab. 1981, 3, 25-110.

15. Wood, O.L.; Moussa, M.I.; Hoogstraal, H.; Biittiker, W. Kadam Virus (Togaviridae, Flavivirus) infecting camel-parasitizing Hyalomma dromedarii ticks (Acari: Ixodidae) in Saudi Arabia. J. Med. Entomol. 1982, 19, 207-208. [CrossRef] [PubMed]

16. Bazlikova, M.; Kazar, J.; Schramek, S. Phagocytosis of Coxiella burnetii by Hyalomma dromedarii tick haemocytes. Acta Virol. 1984, 28, 48-52.

17. Lange, J.V.; El Dessouky, A.G.; Manor, E.; Merdan, A.I.; Azad, A.F. Spotted Fever Rickettsiae in Ticks from the Northern Sinai Governate, Egypt. Am. J. Trop. Med. Hyg. 1992, 46, 546-551. [CrossRef]

18. de la Fuente, J.; Villar, M.; Cabezas-Cruz, A.; Estrada-Pena, A. Tick-Host-Pathogen Interactions: Conflict and Cooperation. PLoS Pathog. 2016, 12, 1-7. [CrossRef]

19. Hoogstraal, H.; Valdez, R. Ticks (Ixodoidea) from wild sheep and goats in Iran and medical and veterinary implication. Fieldiana Zool. 1980, 6, 1-16.

20. Wikel, S.K. Ticks and tick-borne infections: Complex ecology, agents, and host interactions. Vet. Sci. 2018, 5, 60. [CrossRef]

21. Morzaria, S.; Katende, J.; Kairo, A.; Nene, V.; Musoke, A. New methods of diagnosis of Babesia bigemina infection. Mem. Inst. Oswaldo Cruz. 1992, 87, 201-205. [CrossRef]

22. Suleiman, S.Y.A. Geophysical and Hydrogeological studies of Al-Foah area, North Al Ain, United Arab Emirates (UAE). Master's Thesis, Water Resources Program, United Arab Emirates University, Al Ain Abu Dhabi, UAE, 2007; pp. 1-115.

23. Anullo, A.; Alemu, B.; Ayele, M. Study on major cattle ectoparasites in and around Adama, Central Ethiopia. Nat. Sci. Res. 2018, 8, 1-6.

24. Zeleke, M.; Bekele, T. Species of ticks on camels and their seasonal population dynamics in Eastern Ethiopia. Trop. Anim. Heal. Prod. 2004, 36, 225-231. [CrossRef] [PubMed]

25. Hoogstraal, H. African Ixodoidae: Ticks of Sudan (with Special Reference to Equatoria Province and with Preliminary Reviews of the Genera Boophilus, Margaropus, and Hyalomma); BHL: Cairo, Egypt, 1956; Department of Medical Zoology, United States Naval Medical Research Unit No. 3; Volume 1, pp. 1-1105.

26. Walker, A.R.; Bouattour, A.; Camicas, J.-L.; Estrada-Peña, A.; Horak, I.G.; Latif, A.A.; Pegram, R.G.; Preston, P.M. Ticks of Domestic Animals in Africa: A Guide to Identification of Species; Bioscience Reports: Edinburgh, UK, 2003; ISBN 095451730X.

27. Al-Deeb, M.A.; Muzaffar, S. Bin Prevalence, distribution on host's body, and chemical control of camel ticks Hyalomma dromedarii in the United Arab Emirates. Vet. World. 2020, 13, 114-120. [CrossRef] [PubMed]

28. Gharbi, M.; Etta1, M.; Sassi, L.; Dridi, W.; Darghouth, M.A. Hyalomma scupense (Acari, Ixodidae) in northeast Tunisia: Seasonal population dynamics of nymphs and adults on field cattle. Parasite 2013, 20, 1-8. [CrossRef] 
29. Benchikh-Elfegoun, M.; Benakhla, A.; Bentounsi, B.; Bouattour, A.; Piarroux, R. Identification and seasonal kinetics of parasitic ticks in cattle in the region of Taher (Jijel) Algeria. Ann. Vet. Med. 2007, 151, 209-214.

30. Van Straten, M.; Jongejan, F. Ticks (Acari: Ixodidae) infesting the Arabian Camel (Camelus dromedarius) in the Sinai, Egypt with a note on the acaricidal efficacy of Ivermectin. Exp. Appl. Acarol. 1993, 17, 605-616. [CrossRef]

31. Alahmed, A.M.; Kheir, S.M. Life cycle and survival of Hyalomma dromedarii (Acari: Ixodidae) under laboratory conditions. Agric. Mar. Sci. 2003, 8, 11-14.

32. Ouhelli, H. Comparative development of Hyalomma marginatum (Koch, 1844), H. detritum (Schulze, 1919), H. anatolicum excavatum (Koch, 1844), H. lusitanicum (Koch, 1844) and H. dromedarii (Koch, 1844) under laboratory conditions. Acta Parasitol. 1994, 39, 153-157.

33. Apanaskevich, D.A.; Schuster, A.L.; Horak, I.G. The genus Hyalomma: Vii. redescription of all parasitic stages of H. (Euhyalomma) dromedarii and H. (E.) schulzei (Acari: Ixodidae). J. Med. Entomol. 2008, 45, 817-831. [CrossRef]

34. Pomerantzev, B.I. Ixodid Ticks (Ixodidae); Fauna USSR Arachnida; Elbl, A., Translator; American Institute of Biological Sciences: Washington, DC, USA, 1959; Volume IV.

35. Diab, F.; Al-Khalifa, M.; Al-Asgah, N.; Hussein, H.; Khalil, G. Ticks (Acari: Argasidae, Ixodidae) infesting livestock in Saudi Arabia. Fauna Arab. 2006, 22, 233-243.

36. Hoogstraal, H.; Traylor, M.A.; Gaber, S.; Malakatis, G.; Guindy, E.; Helmy, I. Ticks (Ixodidae) on Migrating Birds in Egypt, Spring and Fall 1962. Bull. World Health Organ. 1964, 30, 355-367.

37. Al-Khalifa, M.; Diab, F.; Al-Asgah, N.; Hussein, H.; Khalil, G. Ticks (Acari: Argasidae, Ixodidae) recorded in wild animals in Saudi Arabia. Fauna Arab. 2006, 22, 225-232.

38. Hniche, M. Identification des Tiques et Dépistage de l'infection Piroplasmique des Bovins au Sein d'un élevage Mixte de Bovins et de Dromadaire dans le sud Ouest de la Tunisie. Ph.D. Thesis, Veterinary Medicine Sidi Thabet, Tunisia: Ecole Nationale de Médecine Vétérinaire. Méd. Vét. E.N.M.V., Sidi Thabet, Tunisia, 2006.

39. Al-Deeb, M.A.; Bin Muzaffar, S.; Abu-Zeid, Y.A.; Enan, M.R.; Karim, S. First record of a spotted fever group Rickettsia sp. and Theileria annulata in Hyalomma dromedarii (Acari: Ixodidae) ticks in the United Arab Emirates. Florida Entomol. 2015, 98, 135-139. [CrossRef] 